\title{
LEITURA MERLEAU-PONTYANA DA TEORIA FENOMENOLÓGICA DA EXPRESSÃO
}

Marcos José Müller

SINTTESE - A tese de Husserl - segundo a qual, os signos (expressivamente empregados) haveriam de encamar nossos pensamentos - formeceu o ponto de partida ao projeto merleau-pontyano de restituição "filosófica" de nosso contato com o mundo da percepção. Porquanto seriam gestos instituidos por nosso corpo, os signos (expressivamente empregados) remeteriam a reflexão filosófica à experiência sensível e, conseqüentemente, ao mundo da percepção revelado por essa experiência. Mais do que isso, os signos (expressivamente empregados) esclareceriam a origem sensível dos pensamentos. O que acabaria por suspender a própria tese fenomenológica de que os pensamentos seriam o desdobramento dos atos de uma consciência pura. A interpretaçäo merleau-pontyana da teoria fenomenológica da expressão mostrou que, tal como os pensamentos, a consciência de nós mesmos seria tributária da experiência sensivel.

PALAVRAS-CHAVE - Merleau-Ponty. Husserl. Fenomenologia. Expressão.
ABSTRACT - Husserl's claim according to which signs (when expressively employed) are supposed to embody our thoughts provided the starting point for the Merleau-Pontyan project of the "philosophical" restoration of our contact with the world of perception. As gestures instituted by our body, signs (when expressively employed) would refer the philosophical reflection to sensory experience and, as a consequence, to the world of perception which such an experience reveals. More importantly, signs (when expressively employed) are supposed to reveal the origin of thoughts in sensory experience, which would lead to the supression of the very phenomenological thesis that thoughts are a consequence of the acts of a pure awareness. The Merleau-Pontyan interpretation of the phenomenological theory of expression has shown that, as is the case with thoughts, the awareness of ourselves is dependent on sensory experience. KEY WORDS - Merleau-Ponty. Husserl. Phenomenology. Expression.

Das muitas nuanças implícitas ao projeto fenomenológico de Husserl, aquela que, mais intensamente, repercutiu na filosofia merleau-pontyana foi a expressa nos termos do mote "retornar às coisas mesmas". Em certo sentido, não exageraria se dissesse que toda filosofia merleau-pontyana poderia ser tomada como um comentário desse mote. Afinal de contas, foi nos termos desse mote que Merleau-

Professor do Departamento de Filosofia da Universidade Federal de Santa Catarina. 
Ponty fez a critica da ontologia naturalista subjacente aos discursos críticos acerca dos fenômenos. Mais do que isso, foi nos termos daquele mote que Merleau-Ponty propôs o principal desafio de sua filosofia, a saber, a consideração dos fenômenos não a partir de um sistema de pensamentos já constituídos e sedimentados como modelo ontológico, mas a partir da experiência em que os fenômenos primeiramente se manifestariam para nós. Entrementes, em que termos um discurso pode retomar as "coisas mesmas"? A teoria fenomenológica da expressão deveria fornecer a resposta.

De fato, numa carta de apresentação dirigida a Martial Guéroult - e na qual resumira seus feitos e propósitos em filosofia até então, procurando, assim, habilitar-se a um posto no Collège de France - Merleau-Ponty disse que a intenção primeira da Phénoménologie de la perception seria preterir a ontologia naturalista em proveito de uma nova ontologia, capaz de restituir os fenômenos, tais como eles se nos manifestassem no mundo da percepção (Merleau-Ponty, 1962:402). Como sabemos, para as ontologias de inspiração naturalista, o mundo não se distinguiria de um aglomerado de partes extensas e exteriores entre si, cuja unidade nós tão somente poderíamos representar; e desde que apelássemos às propriedades associativas ou categorias da subjetividade. Os fenômenos seriam essas representações e toda a questão se resumiria em discutir a legitimidade dessas representações. É somente aqui que podemos reconhecer uma desinteligência entre os próprios naturalistas, sendo mérito de Merleau-Ponty - nesse aspecto, especificamente - ter mostrado que, do ponto de vista ontológico, tanto o cartesianismo intelectualista quanto o empirismo inglês são cúmplices do naturalismo (Merleau-Ponty, 1945:49). Ora, mesmo tendo reconhecido haver diferenças que incompatibilizavam essas teorias entre si, a Phénoménologie de la perception compreendeu e censurou, nelas, o defeito comum de não levarem em conta o processo por cujo meio puderam tomar aos fenômenos como representações. Ou, então, Merleau-Ponty acusou os naturalistas de omitirem a gênese das teses ontológicas, por cujo meio puderam distinguir entre um mundo em-si e um mundo de representações subjetivas. Afinal de contas, a consideração ontológica do mundo é sempre tardia em relação à experiência por meio da qual o mundo primeiramente se nos manifesta. Ou, então, nossos pensamentos são tributários em relação às experiências perceptivas. O próprio cartesianismo o admitia, frisou Merleau-Ponty, ao lembrar aquela famosa passagem em que Descartes disse ser somente por meio da vida e das conversações comuns [...] que se aprende a conceber a união da alma e do corpo ${ }^{1}$. Eis por que razão, acreditava Merleau-Ponty, haveria que se

1 Como indica Merleau-Ponty (1945, p. 53), Descartes diz que o entendimento se sabe incapaz de conhecer a união entre a alma e o corpo; e deixa para a vida conhecê-la: "Os pensamentos metafisicos, que exercitam o entendimento puro, servem para nos tomar familiar a noção de alma; e o estudo das matemáticas, que exercita principalmente a imaginaçāo na consideração das figuras e dos movimentos, nos acostuma a formar noções do corpo bem distintas; e, enfim, usando somente a vida e as conversações comuns e abstraindo-se de meditar e estudar as coisas que exercitam a imaginação, é que se aprende a conceber a união da alma e do corpo" (Descartes, 1641, p. 301302). 
restituir a primordialidade das experiências, pois seriam elas a ocorrência primitiva dos fenômenos, das coisas mesmas: Entretanto, em que termos uma reflexão poderia restituir a primordialidade da experiência? Para fazê-lo, ela não precisaria de pensamentos? Mas, ao recorrer a tais pensamentos, ela não sobrepujaria, tal qual o naturalismo, as experiências e, por extensão, os fenômenos que essas experiências revelariam? Ou, conforme a alternativa contrária, a restituição da experiência não implicaria uma renúncia aos pensamentos? Mas, nesse caso, em que sentido eu poderia ainda falar em ontologia, em reflexão nos fenômenos, em filosofia? O projeto merleau-pontyano não ensejaria um paradoxo irretorquível, do qual eu só sairia se abandonasse os pensamentos em proveito da vida, como sugeriu Bréhier ao próprio Merleau-Ponty, por ocasião de um debate realizado na Sociedade Francesa de Filosofia, em 1946? ${ }^{2}$

Conforme penso, é na fenomenologia husserliana, outra vez, que MerleauPonty encontrou uma alternativa de resposta a essas objeções dirigidas à Phénoménologie de la perception. Mais precisamente, é junto à teoria da expressão lingüística - primeiramente apresentada nas Investigações lógicas, mas retomada, por Husserl, nas obras tardias - que Merleau-Ponty encontrou aquilo que se poderia considerar o ponto de tangência entre a reflexão filosófica e as experiências de que os fenômenos seriam indissociáveis. Na avaliação de Merleau-Ponty, quando Husserl reconheceu que - ao exprimir - nossas palavras corporificam nossos pensamentos, ele fez mais do que refutar a explicação empirista para a experiência falante. Ou, então, ele introduziu mais do que uma contraposição à tese de que as palavras seriam o efeito exterior de uma causa neuropsíquica. Husserl admitiu para a fala e para os pensamentos uma relação interna, muito semelhante àquela que haveria de existir entre os fenômenos percebidos e a experiência perceptiva, julgou Merleau-Ponty. Para usar uma metáfora leibniziana, o vínculo interior - que Husserl reconhecia viger entre a fala expressiva e o pensamento - "espelharia" o vínculo que imbricaria as coisas percebidas e a experiência da percepção. De onde Merleau-Ponty inferiu a consequiência de que, se a reflexão pudesse pretender

2 Em 23 de novembro de 1946, no debate que sucedeu à exposição que Merleau-Ponty fez para a Sociedade Francesa de Filosofia, Bréhier procura inferir da proposta merleau-pontyana de "retomada de nosso contato com o mundo da percepção" uma conseqüência desabonadora. Segundo Bréhier, para não ser contraditória, a doutrina de Merleau-Ponty deveria permanecer nảo-formulada, apenas vivida como um retomo ao imediato. Todavia, continua ele, em que medida uma doutrina somente vivida é ainda uma filosofia? (Merleau-Ponty, 1947, p. 71). Ao que Merleau-Ponty responde dizendo: "[s]eguramente uma vida não é uma filosofia. Acreditava ter indicado de passagem a idéia de que a descrição não é um retorno ao imediato; não se volta a ele. Trata-se simplesmente de saber se nos propomos compreendê-lo. Parece-me que buscar a expressão do imediato não é trair a razão, é, ao contrário, trabalhar para o seu engrandecimento. [...] É começar a luta entre a expressão e o expresso, é aceitar a condição de uma reflexão iniciante. $O$ que nos encoraja é que não há vida pura e absolutamente inexpressa no homem, é que o irrefletido só começa a existir para nós através da reflexão. Entrar nessas contradiçōes [...], parece-me, isto faz parte do inventário crítico de nossa vida, que é a filosofia" (Merleau-Ponty, 1947, p. 71-2). Em 23 de maio de 1946, numa entrevista concedida a Maurice Fleurent, Merleau-Ponty resume sua proposta de trabalho (apresentada na Phénoménologie de la perception) dizendo: "[a] filosofia tem por tarefa fazer-nos reencontrar esta ligação com o mundo que precede o pensamento propriamente dito" (1946, p. 66). 
restituir a experiência, tal se deveria a que ela própria comportasse uma experiência e, conseqüentemente, seria no seio da própria reflexão que aquela restituição haveria de ser estabelecida. Eis em que sentido Merleau-Ponty falaria de uma reflexão radical que, mais do que descrever as várias experiências de que os fenômenos seriam desdobramentos, procuraria descrever a ela própria, para reencontrar nela mesma a experiência irrefletida do mundo (Merleau-Ponty, 1945:2789). Tal como Schelling - que compreendeu, na finitude da reflexão, o princípio no qual a filosofia devia se pautar para refletir na natureza finita - Merleau-Ponty vislumbrou, na inexorável gestualidade verbal (por cujo meio nossos pensamentos são propriamente exprimidos), o ponto de tangência entre a reflexão e as demais experiências de nossa existência.

O fato de Merleau-Ponty ter inferido da teoria da expressão de Husserl uma conseqüência ontológica não haveria de implicar, evidentemente, que Husserl concebesse tal conseqüência, ou, então, que a teoria husserliana da expressão ensejasse algo como uma ontologia, de que a experiência da fala fosse a ocorrência exemplar. A construção de uma ontologia que pudesse rivalizar com o naturalismo não era, para Husserl, um problema fenomenológico. O naturalismo não carecia de ser destruído. Ele deveria ser fundamentado em condições apodíticas (Husserl, 1950, p. 44-45). Ainda que, em textos posteriores às Investigações lógicas (tais como Lógica formal e lógica transcendental, ou Origem da geometria), Husserl admitisse tomar os signos não apenas como um corpo inerte (Körper), mas como a came viva (Leib) de nossos pensamentos, ainda que os considerasse a realização intersubjetiva de nossas intenções significativas, daí não se seguia que prescindisse da tese (de inspiração naturalista), segundo a qual, aquém de nossa fala, subsistiria uma atividade subjetiva, de que os signos expressivos, quando muito, seriam apenas uma encarnação (Verleiblich). Reside aqui, justamente, o limite entre a teoria da expressão de Husserl e a leitura que dela fez MerleauPonty. Compreender esse limite é mais do que estabelecer uma diferença de perspectiva, é compreender em que sentido, em Merleau-Ponty, a teoria fenomenológica da linguagem transforma-se em ontologia.

A tese segundo a qual nossas palavras não seriam completamente exteriores aos nossos pensamentos, podendo a eles "significar", Husserl a apresentou pela primeira vez nas Investigações lógicas (Husserl, 1900). Conforme a primeira das Investigações lógicas, deveríamos distinguir entre aqueles signos que simplesmente "indicariam" outro estado-de-coisas e aqueles signos que "expressariam", neles próprios, uma significação. Todavia, como observou Derrida (1967:28), por meio dos termos indicação e expressão, Husserl pretendia sinalizar mais uma distinção no modo de funcionamento dos signos, e menos uma distinção essencial. Ademais, essa distinção seria antes jurídica do que factual, uma vez que também os 
signos expressivos poderiam cumprir uma função indicativa, embora a alternativa contrária não fosse verdadeira para Husserl ${ }^{3}$. Um signo indicaria algo quando aparecesse como o motivo a partir do qual poderíamos compreender ou presumir 0 surgimento de outra coisa, sem que para tanto precisássemos considerar a intenção de quem o apresentasse. Um signo expressivo, por sua vez, seria o que daria a conhecer, antes de tudo, a intenção do sujeito falante; seria aquele que revelaria o que o sujeito falante quisesse-dizer. Num signo expressivo, mais do que a indicação de algo, chamar-se-ia à liça um conteúdo visado pelo sujeito falante, trar-se-ia à baila a significação conceitual que ele quisesse caracterizar (ou, como prefere Derrida, que ele quisesse-dizer). ${ }^{4}$ A expressão, portanto, seria para Husserl a exteriorização voluntária de algo que estivesse formulado no interior do sujeito de quem o signo seria uma extensão corporal. Não haveria expressão sem a intenção de um sujeito animando o signo, não haveria expressão sem que aquele emprestasse a este sua espiritualidade (Geistigkeit). Eis por que, em cada signo expressivo, Husserl distinguiu uma parte física (o signo sensível, o complexo vocal articulado, o signo escrito sobre o papel) e uma parte propriamente expressa, a saber, os atos intencionais (Husserl, 1900, tomo I, §9, 242-3) De fato, seriam tais atos que haveriam de fornecer aos signos seu sentido e, eventualmente, sua plenitude intuitiva. ${ }^{5}$ Husserl estaria aqui muito próximo do naturalismo intelectualista dos psicólogos, os quais admitiriam, aquém dos signos que enunciássemos, um núcleo irradiador de significados, uma atividade categorial, de que os signos seriam apenas um modo de explicitação dirigido ao outro. Não apenas isso, tal como os psicólogos intelectualistas, Husserl teria admitido entre os signos e os significados produzidos por nossa atividade intencional uma relação de plena equivalência, 0 que haveria de tornar a linguagem um empreendimento ideal. Eis por que pôde propor-se construir uma eidética universal da linguagem, uma gramática universal de todas as línguas empíricas possiveis, de sorte que os atos da fala e as línguas existentes fossem apenas a exibição factual da essência da linguagem (Husserl, 1900, tomo I, §14, 466-467).

Nas obras tardias, entretanto, Husserl não mais falaria em gramática universal de todas as línguas empíricas possiveis. A experiência comunicativa mostrou que os signos expressivos não eram apenas o acompanhamento físico de nossos atos significativos. Mais do que isso, eles teriam de ser a encamação (Verleiblich) de nossas intenções significativas junto à comunidade de falantes, o que esclareceria a possibilidade da comunicação e o estabelecimento das diferentes línguas empí-

3 Diz Husserl: "Todo signo é signo de algo; mas nem todo signo tem uma significação [Bedeutung], um 'sentido' [Sinn], que esteja expresso por um signo" (Husserl, 1900, tomo I, §1, 233).

4 Conforme Derrida, "[p]oderíamos traduzir bedeuten por querer-dizer [vouloir-dire em francês], a um só tempo, no sentido em que um sujeito falante, 'exprimindo-se', como diz Husserl, 'sobre alguma coisa', quer dizer, e no sentido em que uma expressão quer dizer, e assegurarmo-nos de que a Bedeutung é sempre 'aquilo que' alguém ou um discurso 'querem dizer': sempre um sentido de discurso, um conteúdo discursivo" (Derrida, 1967, p. 26).

5 Para Husserl, os significados expressos não são suficientes para assegurar o conhecimento de um objeto. Para tanto, é necessário que tais significados sejam preenchidos com intuições, sem o que permaneceriam apenas como flatus vocis (Husserl, 1900, tomo I, \$13-4, 250 e ss.). 
ricas. Encarnando nossas intenções significativas, os signos haveriam de nos conduzir até o outro, estabelecendo entre nós e eles uma espécie de "ponte", por cujo meio nos comunicaríamos (Husserl, 1929, 20, 3). Era tal encarnação o que Husserl tinha em vista quando disse que a linguagem exprime uma intenção. Acolhendo nossas intenções significativas, cada um de nossos signos deixaria de ser uma unidade meramente física (Körper), para se tornar uma "corporeidade espiritual" (Geistige Leiblichkeit), uma carne (Leib) lingüística, por meio da qual nos expriminiamos para outrem (Husserl, 1929, p. 19). Nossas intenções, por sua vez, não precisariam de nenhum signo para estar presentes a si mesmas ${ }^{6}$. Como disse Derrida, é tanto contra esses signos quanto graças a eles que nossas intenções significativas despertariam e se manteriam em vida (Derrida, 1967, p. 92-93). Ora, eis aqui a face tradicional da teoria da expressão de Husserl. Ainda que reconhecesse nos signos um corpo espiritual, mesmo que identificasse neles a came de meus significados conceituais, para Husserl, se os signos exprimem tais significados, é porque estão animados (sinnbelebt) pela atividade intencional de minha consciência. Para Husserl, enfim, os signos continuavam sendo um meio para a consciência, jamais a própria geração de um significado.

III

As significações - acredita Merleau-Ponty - não carecem de ser primeiramente representadas num domínio que, sobrepondo-se à contingência de nossa experiência, assegurasse a diferença e a identidade dos dados ou impressões percebidos. Ou, então, nossas palavras não exprimem porque estão animadas por atos intencionais autônomos e presentes a si. Afinal de contas, se esses atos fossem autônomos e presentes a si, por que exigiriam a fala? Por que tenderiam para a fala como que para seu acabamento? Os pensamentos não se bastariam? Mas, nesse caso, como explicar que o objeto mais familiar parece-nos indeterminado enquanto não encontramos uma maneira de designá-lo pela linguagem? Ou, então, por que ignoramos nossas intenções significativas antes de formulá-las com as palavras? (Merleau-Ponty, 1945, p. 206).

Ao contrário da leitura husserliana da relação de dependência que subordinaria as falas aos nossos atos intencionais, para Merleau-Ponty, são nossas intenções que dependem das palavras. Ou, é por meio das palavras que as intenções realizam-se como atos intencionais de fato, pensamentos. Antes das palavras, as intenções são apenas voto mudo, não estando, por conseguinte, formuladas. Nesse sentido, "[o] ato de expressão, essa junção, pela transcendência, do sentido lingüístico da palavra e da significação por ela visada, não é, para nós, sujeitos falantes, uma operação segunda a que recorreriamos apenas para comunicar a outrem nossos pensamentos, mas é a tomada de posse das significações por nós, sua aquisição" (Merleau-Ponty, 1960, p. 112-113). Consideradas enquanto verdadeiros

- É o que podemos perceber em muitas passagens da Origem da geometria de Husserl (Husserl, 1954, p. 83-100). 
gestos de meu corpo, minhas palavras não seriam apenas um meio de expressão. Seriam a própria realização das significações que exprimo, seriam a realização dos pensamentos, da mesma forma como a percepção seria a realização do percebido.

Todavia, admite Merleau-Ponty, o certo é que devemos admitir um privilégio dos pensamentos relativamente aos demais fenômenos exprimidos em nossas experiências (1945, p. 221). Ainda que nenhum pensamento possa se dispensar de uma fala que o crie, depois de falados, os pensamentos podem ser retomados numa fala segunda, sem que, para isso, essa fala segunda precise reeditar a fala primeira em todos os seus detalhamentos. Mesmo por meio dessa fala comprimida ou abreviada, os pensamentos permanecem acessiveis, e eis por que razão nossa linguagem pode designar o que ela não é. Eis por que ela pode representar, ou, o que é a mesma coisa, apresentar um pensamento por meios que não aqueles originariamente empregados. Todavia, inebriados por essas ocorrências - que acreditamos tratar-se de algo silente - paulatinamente, vamos esquecendo o papel desempenhado pelas palavras. A partir de então, começamos a considerar os pensamentos independentemente das palavras, como se se tratasse de ocorrências puras. Damo-nos a ilusão de uma vida interior, admitindo - aquém de cada experiência - um "pequeno interior", um piloto em seu navio (Merleau-Ponty, 1945, p. 213). Mais do que isso, passamos a acreditar que essa vida é regida por leis próprias, a qual chamamos de consciência. Frente a essa consciência, nossa fala desempenharia um papel subsidiário, um apoio empírico para a realização da comunicação. E o naturalismo completa seu ciclo, encontrando sua cara-metade: a consciência, a psique.

Ora, é justamente aqui - acredita de Merleau-Ponty - que podemos perceber a virtude da fenomenologia da linguagem de Husserl. Ainda que o conceito de consciência veiculado pela fenomenologia husserliana seja vítima dessa ilusão retrospectiva, ainda que o Ego husserliano seja uma decorrência desse ardil que a própria fala nos preparou (haja vista sua capacidade para permanecer como pensamento já falado), ao refletir na capacidade expressiva dos signos, Husserl pôs sob suspeita a "pureza" dessa vida interior. E - aos olhos de Merleau-Ponty reside, aqui, o maior mérito da fenomenologia da linguagem. Em certo sentido, o reconhecimento de que os signos estão investidos do poder para exprimir relativizou - mesmo que de forma involuntária - essa cara-metade da tese naturalista. Ou, então, Husserl pôs sob suspeita a tese de que nossa consciência seria - em todos os seus aspectos - uma vida interior autônoma. Mesmo assim, Husserl não foi suficientemente radical em sua descrição do poder expressivo da fala, pois, se tivesse sido, haveria de suspender a própria idéia de consciência transcendental, porquanto ela dava sobrevida ao naturalismo. Ele haveria de compreender que a admissão da primordialidade da experiência (ou mundo da vida, na terminologia husserliana) não teria sido suficiente para delivrar os fenômenos do prejuizo naturalista. Enfim, compreenderia que o reconhecimento do poder expressivo da fala ensejava uma nova ontologia, segundo a qual, não apenas os fenômenos expressos, mas também a própria consciência expressiva haveriam de ser um desdobramento da experiência, ou do mundo-da-vida. 
Mas o fato de Merleau-Ponty preterir a tese de que os pensamentos são o resultado de uma capacidade de representação exercida por uma subjetividade exterior às demais experiências, muito especialmente à falante, não implica que ele tivesse refutado a idéia de subjetividade. Na Phénoménologie de la perception Merleau-Ponty fala de um silêncio da consciência, que é a origem de nossos pensamentos, bem como de nossas outras modalidades de significação, o que não quer dizer que essa consciência seja a causa dessas significações. Diz MerleauPonty, "nossa visão sobre o homem continuará a ser superficial enquanto não remontarmos a essa origem, enquanto não reencontrarmos, sob o ruído das falas, o silêncio primordial, enquanto não descrevermos o gesto que rompe esse silêncio" (1945, p. 214). Enquanto ocorrência silenciosa, essa subjetividade é indiscernivel de nossas experiências. Ou, então, ela constitui-se por meio dessas experiências, como se se tratasse do movimento de resistência que as partes de meu corpo manifestariam quando se integrassem numa determinada totalidade ou significação. Trata-se de algo concomitante às significações exprimidas pela experiência e que apenas na margem, nas bordas, ou extremidades, manifestar-se-ia. Como disse Merleau-Ponty, tal como na percepção de um objeto - em que é pelo canto do olho que eu percebo a mim como aquele que percebe (1945:377) - também na fala, é lá na extremidade de meus gestos verbais, para além do expresso, que eu percebo a mim. Por outras palavras, é quando ela a fala escapa ao meu controle, vindo a participar do gesto de outrem, é que eu percebo que havia ou há o eu - o outro do outro.

Encerro dizendo que, ao interpretar a teoria husserliana da expressão, Merleau-Ponty faz mais do que repetir a estratégia de Husserl, que era mostrar o vínculo entre nossas intenções significativas e nossos atos expressivos. Merleau-Ponty tornou a própria consciência desses atos algo relativo a eles. Dessa forma, cumpriu sua intenção programática, que era justamente restituir o caráter originário de nossa experiência na constituição dos fenômenos. O primado da experiência - e ao qual Husserl chamava de mundo da vida - é o nascedouro das significações em que nos polarizamos, das "coisas mesmas". E a expressão é o nome da relação na forma da qual a experiência engendra não apenas essas significações, mas também seu ponto de fuga: nossa subjetividade.

\section{Referências bibliográficas}

DESCARTES, René (1641). Meditaçōes. 2. ed. In: Desscartes. Trad. J. Guinsburg e Bento Prado Júnior. São Paulo: Abril Cultural, 1979. (Col. Os Pensadores)

DERRIDA, Jacques (1967). A voz e o fenômeno: introdução ao problema do signo na fenomenologia de Husserl. Trad. Lucy Magalhães. Rio de Janeiro: Jorge Zahar, 1994.

HUSSERL, Edmund (1900). Investigaciones lógicas. 2. ed. Trad. Manuel G. Morente y José Gaos. Madrid: Alianza, 1985. (2 tomos)

1974

(1929). Formale und transzendentale Logik. Haag: Martinus Nijhoff, Husserliana (Band XVII),

(1950). L'idée de la phénoménologie. 4. ed. Trad. Alexandre Lowit. Paris: PUF, 1990.

(1954). Origine de la géométrie. Trad. Jacques Derrida. Paris: PUF, 1962.

MERLEAU-PONTY, Maurice (1945). Phénoménologie de la perception, Paris: Gallimard.

(1945). Entrevista concedida a Maurice Fleuent [integrada a Parcours, Paris: Verdier, 1997]. 
(1945). O primado da percepção e suas conseqüências filosóficas. Trad. Constança Marcondes Cesar. Campinas: Papirus, 1990.

(1960). Signes, Paris: Gallimard.

(1962). Candidature au Collège de France - un inédit de Merleau-Ponty. Revue de Métaphysique et de Morale, n. 67.

(1964). Le visible et l'invisible, Paris: Gallimard: 